\title{
E eu (ainda) não sou uma mulher? Gênero, interseccionalidade e silêncio racial
}

\author{
Am I (still) not a woman? Gender, intersectionality \\ and racial silence
}

Giovana de Carvalho Castro*

\begin{abstract}
Resumo - A produção historiográfica sobre mulheres no Brasil se constituiu desvinculada da discussão racial, colocando na centralidade das suas análises o corpo branco e silenciado outras subjetividades femininas. Assim, na escuta desse silêncio, analisar as perspectivas dessa construção e seus efeitos sobre a construção de narrativas sobre mulheres no campo historiográfico brasileiro é a base desse artigo. Para tanto, proponho uma breve análise da produção historiográfica sobre mulheres no Brasil, sua gênese vinculada com o feminismo branco e acadêmico para desembocar na defesa da necessidade da racialização dos estudos sobre mulheres e na importância da mirada interseccional como caminho para alcançar essas vozes.

Palavras-chave: história das mulheres no Brasil; gênero; interseccionalidade; mulheres negras.
\end{abstract}

\begin{abstract}
The historiographical production about women in Brazil was disconnected from the discussion about race, placing white bodies at the center of its analysis and silencing other female subjectivities. So, in listening to this silence, the object of this article is to analyze the perspectives of this construction and its effects on the construction of narratives about women in Brazilian historiography. To this end, I propose a brief analysis of the historiographical production about women in Brazil, its linked genesis to white and academic feminism, and end up defending the need for the racialization of studies on women and the importance of the intersectional view as a way to reach these voices.
\end{abstract}

Keywords: history of women in Brazil; gender, intersectionality; black women.

*Doutoranda em História (Universidade Federal de Juiz de Fora). Professora da Rede Municipal de Ensino de Juiz de Fora. E-mail: giovanahistoria@bol.com.br. ORCID: https://orcid.org/0000-0002-6451-9819. 


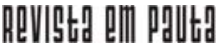

\} E EU (AINDA) NÃO SOU UMA MULHER - CASTRO, G. C. \}

DOI: $10.12957 /$ rep.2021.56086

A História das Mulheres no Brasil é uma história para poucas mulheres, de poucas mulheres, por poucas mulheres. Oriunda de um macromovimento de (re)escrita da História, atrelou-se a questionamentos acerca da impossibilidade de uma história objetiva e da desmistificação das tentativas de narrativas totalizantes e verdadeiras em sua gênese. Além disso, fez coro, unindo-se às outras vertentes historiográficas, à crítica à história dos "grandes homens", às narrativas lineares e progressivas e à uma história que aspirava ser ciência, dando pontapé para uma nova dimensão em termos de pesquisas e produção de narrativas que historicizaram sujeitos antes invisíveis.

Nessa cruzada antiinvisibilidade, historiadoras ${ }^{1}$, em sua maioria, afundaram-se em pesquisas e produções que trouxeram para a História a presença do feminino, possibilitando a construção de novas escritas possíveis, num movimento fortemente influenciado pelas bandeiras do movimento feminista. Por essa ligação umbilical, me atrevo a dizer que uma das questões mais centrais desse movimento foi o desejo de suplantar a mulher como mera condição biológica e reinventá-la como socialmente delineada, pensando suas atuações e vivências em diferentes temporalidades. Esse desejo imprimiu à história das mulheres uma condição sui generis: a de ser um campo de pesquisa fortemente vinculado a um movimento social, impactando diretamente nas produções sobre mulheres ao definir o termo baseado nas experiências das primeiras que chegaram aos bancos universitários. São essas experiências e identidades que irão definir o objeto desse novo campo de pesquisa.

Então, quem é essa mulher da História das Mulheres? É a mulher branca, que, chegando à academia, passou a questionar a universalidade do masculino enquanto categoria analítica num movimento que, antes das historiadoras, foi engendrado pelas feministas. Alinhavado aos movimentos políticos dos anos 1960, esse feminismo é constantemente referenciado como o responsável por apontar a ausência da figura feminina no território historiográfico e, na esteira, questionar os pressupostos epistemológicos que norteavam o mundo do saber.

Do ventre da Nova História dos anos 1970 brotou a tríade articuladora dessas novas produções: novas fontes, novos métodos, novos objetos. O mantra da História Nova implicava trilhar rotas tortuosas que não mais estavam nos grandes arquivos nem nas grandes bibliotecas. A História agora garimpava entre cozinhas e baús, cadernos amarelados e cartas de amor. O privado vira público num revirar de memórias que não disfarça sua avidez pelo detalhe, abrindo espaço ao subjetivo, ao pessoal e ao único. Os anos 1980 foram testemunhas das primeiras produções de narrativas históricas sobre mulheres, recheadas de análises sobre como elas sofriam com a dominação patriarcal e a opressão em suas mais variadas facetas, presas

${ }^{1}$ Evidencio aqui os trabalhos de historiadoras precursoras como Margareth Rago, Rachel Soihet e Mary del Priore. 


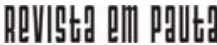

\} E EU (AINDA) NÃO SOU UMA MULHER - CASTRO, G. C. \}

DOI: $10.12957 /$ rep.2021.56086

fáceis que eram mediante as torturas de um mundo feito para adestrá-las através dos meios mais vis e cruéis.

Pesquisadoras, dentre elas Mary Del Priore, Margareth Rago e Rachel Soihet, somadas a nomes como Leila Algranti, Andrea Borelli e Eni Samara ${ }^{2}$, bradaram contra essa essencialização e foram garimpar nas fontes outras possibilidades de analisar o feminino na História. Encontraram inúmeros episódios nos quais as presas lutaram contra as diversas formas de aprisionamento e controle que lhes eram imputados. Nessa busca, novas ferramentas foram se incorporando e os estudos de gênero viraram chave de apelo universal para questionar como essas resistências se constituíram em contextos sobre os quais, até então, se pensava encarar a desigualdade entre homens e mulheres como natural.

Mas a armadilha posta aqui é que essa produção, atravessada pela atuação de feministas brancas de classe média, deixou cristalizada uma mulher universal, assim como a historiografia clássica reificou um homem universal. Foram desconsideradas outras formas de ser mulher, geradas pelo atravessamento de relações de poder, produtoras de distintas experiências históricas e culturais.

As pressões e demandas do movimento feminista, desde os anos 70, assim como a entrada maciça das mulheres no mercado de trabalho e na vida acadêmica forçaram uma quebra do silêncio das historiadoras. $\mathrm{O}$ alargamento temático e as novas produções intelectuais resultantes merecem, hoje, uma avaliação crítica. Esta reflexão se faz tanto mais necessária, quanto mais nos damos conta de que a História não narra o passado, mas constrói um discurso sobre este, trazendo tanto o olhar quanto a própria subjetividade daquele que recorta e narra, à sua maneira, a matéria da história. Além do mais, vale dizer que se esta produção não se caracteriza como feminista, nem significou um questionamento prático das relações de poder entre os sexos na academia, ela carrega traços evidentes de uma vontade feminina de emancipação. (RAGO, 1995, p. 81).

A construção desse discurso utilizou como balizas as premissas de que a emancipação feminina estava diretamente ligada à superação do jugo masculino, apoiando-se na ideia de que a entrada de mulheres no mercado de trabalho se dá, de forma mais intensa, a partir dos anos 1970. Cria direta da história social, a história das mulheres se fez assim, assentada sob a perspectiva de lançar uma mirada sobre as opressões masculinas e capitalistas (RAGO, 1995), dando pontapé a uma série de publicações que perfilam lutas femininas, em diferentes temporalidades. O problema? Elas o fazem serenamente, desvinculadas da discussão racial, levando-nos à necessidade de evidenciar que são muitos os motores que alimentaram a manutenção dessa invisibilidade.

${ }^{2}$ Para mais informações sobre a historiografia das mulheres no Brasil, sugiro Matos (2013). 


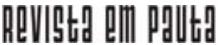

\} E EU (AINDA) NÃO SOU UMA MULHER - CASTRO, G. C. \}

DOI: $10.12957 /$ rep.2021.56086

Deixando de lado por um momento as inúmeras diferenças metodológicas e temáticas que particularizam cada um destes (primeiros) estudos (sobre mulheres), destaco alguns pontos comuns que permitem aproximá-los. Em todos eles, registra-se uma forte preocupação em resgatar a presença de mulheres pobres e marginalizadas, trabaIhadoras ou não, como agentes da transformação, em mostrar como foram capazes de questionar, na prática, as inúmeras mitologias misóginas elaboradas pelos homens de ciência para justificar sua inferioridade intelectual, mental e física em relação aos homens e sua exclusão da esfera dos negócios e da política. Além disso, estes estudos estiveram voltados para fazer emergir um universo feminino próprio, diferente, mas não inferior, do mundo masculino e regido por outra lógica e racionalidade. Todas estas historiadoras revelam uma aguda percepção do feminino e trazem enorme contribuição para a desconstrução das imagens tradicionais das mulheres como passivas e incapazes de vida racional e de decisões de peso. (RAGO, 1995, p. 83).

Em primeiro lugar, fica evidente que esse resgate, fundante de um novo discurso, manteve-se imerso na lógica colonial e inerte ao não pensar a importância da racialização das relações intra e intergêneros. Ademais, ainda que a inserção do gênero enquanto categoria analítica tenha ampliado a semântica para além das mulheres ao trazer uma perspectiva relacional, que leva em conta não só como se tornar mulher, mas também como o fazer sendo cerceada pela opressão masculina, também claudicou severamente ao partir de um viés eurocentrado e marcado pela branquidade. Em questão estava não apenas a mulher que é oprimida, mas também suas subjetividades, numa constituição societária que Ihe dizia tudo sobre o não ser, sem lhe permitir visionar a possibilidade de estar.

A despeito das discussões entre as teóricas do feminismo em torno de uma definição precisa do gênero, é evidente a preocupação em evitar as oposições binárias fixas e naturalizadas, para trabalhar com relações e perceber por meio de que procedimentos simbólicos, jogos de significação, cruzamentos de conceitos e relações de poder nossas referências culturais são sexualmente produzidas. É nesse sentido que os novos estudos feministas se aproximam da história cultural. Com esta nova proposta metodológica, insiste-se em que consideremos as diferenças sexuais enquanto construções culturais, desmontando e sexualizando conceitualizações que fixam e enquadram os indivíduos, seus gestos, suas ações, suas condutas e representações. Negase, portanto, que se parta de uma 'realidade objetiva', em que os sujeitos localizados em classes sociais entrariam em cena segundo um procedimento metodológico homogeneizador e generalizante, que visa a estabelecer continuidades no emaranhar dos fatos, e que entende que interpretar significa recolher (e não atribuir) o sentido essencial 'oculto' na coisa. Além disso, propõe-se pensar as relações de gênero enquanto relações de poder, e nesse sentido a dominação não se localiza num ponto fixo, num 'outro' masculino, mas se constitui nos jogos relacionais e de linguagem. (RAGO, 1995, p. 88). 


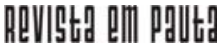

\} E EU (AINDA) NÃO SOU UMA MULHER - CASTRO, G. C. \}

DOI: $10.12957 /$ rep.2021.56086

Num segundo aporte ressalto a cegueira semântica que perpassa a pesquisa historiográfica. Ainda que as metodologias oriundas dos estudos de gênero tenham oportunizado uma abertura de olhares a partir da perspectiva de como se organizam os poderes, perduram ainda as análises que insistem em apontar as relações de dominação, a opressão sexual e o patriarcalismo como elementos que afetam todas as mulheres, mesmo que essas estejam em diferentes lugares nas estruturas socioeconômico-históricas.

A raça fica mais uma vez de fora em função do privilégio das pesquisadoras brancas de não serem racializadas e, por conseguinte, não racializarem suas pesquisas. Essa opção metodológica tem efeitos nefandos sobre a produção acadêmica ao constituir as identidades de mulheres brancas desvinculadas das identidades de mulheres negras. Assim, jogamse por terra quaisquer possibilidades de uma leitura de fato relacional das atuações destas na construção das narrativas históricas. Na base dessa orientação analítica está a idealização da identidade branca, ferramenta central para compreensão de como corpos brancos e não brancos estruturam suas interrelações. Ou seja, calar sobre isso obstaculiza severamente caminhos para um exercício historiográfico legítimo.

Há uma tendência [...] de considerar o racismo como 'algo que tem a ver com a presença de pessoas negras'. Mas é importante salientar que tanto negros como brancos experimentam seu gênero, classe e sexualidade através da 'raça'. A racialização da subjetividade branca não é muitas vezes manifestamente clara para os grupos brancos, porque 'branco' é um significante de dominância, mas isso não torna o processo de racialização menos significativo. É necessário, portanto, analisar que nos constroem como, digamos, 'mulher branca' ou 'muIher negra', como 'homem branco' ou 'homem negro'. Tal desconstrução é necessária se quisermos decifrar como e por que os significados dessas palavras mudam de simples descrições a categorias hierarquicamente organizadas em certas circunstâncias econômicas, políticas e culturais. (BRAH, 2006, p. 345).

Assim se afigura uma questão flagrantemente ignorada por essas produções: a diferença entre homens e mulheres não é a única que invisibiliza, oprime e coíbe uma escrita da História comprometida com a diversidade dos protagonistas que a compõem. Essa leitura em muito se deve à anteriormente delineada cegueira que oportunizou a constituição de um contradiscurso antipatriarcal, antimachista, antissexista, criador de uma superidentidade feminina que se fixou como categoria epistêmica baseada no consenso de que, em todos os tempos e sob quaisquer condições, todas a mulheres tiveram como eixo privilegiado de enfrentamento a opressão sexual exercida pelos homens e o desejo da conquista da cidadania. $\mathrm{O}$ problema dessa pseudoinclusão é que ela deixou de fora dados centrais de análise para uma efetiva compreensão da mulher na história de sociedades 


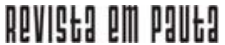

\} E EU (AINDA) NÃO SOU UMA MULHER - CASTRO, G. C. \}

DOI: $10.12957 /$ rep.2021.56086

diaspóricas: a raça e a classe construídas pelo viés da tradição escravocrata e moldadas pela força implacável do colonialismo.

\section{A centralidade da raça como eixo para uma historiografia de mulheres}

A visceralidade dessa assunção liga-se diretamente à importância de estabelecer uma vinculação entre pesquisas historiográficas acerca de mulheres negras e à necessidade de as lermos como corpos diaspóricos, oriundos de um processo que marca a forçada introdução da população negra na sociedade brasileira, colocando frente a frente dois mundos numa hierarquização marcada pelo poder, pela violência e pela subjugação. Além disso, traz à tona a necessidade de compreender que é também da diáspora que nascem as matrizes de construção de subjetividades sobre as quais se ergueram as estratégias de aglutinação e resistência de mulheres negras ao longo da nossa história, tendo como eixo condutor as águas do Atlântico. Essa atlanticidade é aqui definida como um processo de constituição de existência forjado a partir de uma quadruplicidade basilar: tradição escravocrata, constituição identitária, exploração colonial e construção dos racismos. Oportuniza-se, assim, a possibilidade de olhar essas mulheres através de uma perspectiva delineada pela forma como suas memórias estão associadas a uma rede que lhes é anterior, como evidenciado por Beatriz Nascimento:

Mais como metáfora do que como uma generalização de uma concepção de um segmento étnico-cultural e religioso para todos(as) os africanos(as) e todos(as) os(as) negros(as), Beatriz burila o termo Ori, como relação entre intelecto e memória, entre cabeça e corpo, entre pessoa e terra, correlação adequada para se interpretar numa única visada restauradora a desumanização do indivíduo negro e suas possibilidades de reconstrução de si, como parte de uma coletividade. (RATTS, 2006, p. 61 - Grifos nossos).

Da desumanização oriunda da tradição escravocrata emana o silenciamento lacrado, marcado pelas políticas de negação que transformaram a questão da escravidão num tabu; das cozinhas ainda timidamente chega às salas, bem como demonstra a timidez das discussões acerca de seus efeitos sobre homens e mulheres. Inegável é que essa historicidade afetou sobremaneira as existências desses sujeitos, fazendo com que a constituição identitária se tornasse um capítulo complexo na escrita da história das mulheres negras.

Defendo que a ratificação dessa desumanização na historiografia esteja vinculada ao fato de que mulheres negras não foram lidas como muIheres até que começassem a escrever suas próprias histórias. A começar 
pela própria conceituação do feminino em si excludente ao se conformar a definir exclusivamente mulheres brancas heterossexuais, obrigando a adjetivações várias. Dessa maneira, de formas periféricas, abriga mediante intermináveis reinvindicações a inserção no feminino de outras formas: mulher negra, mulher indígena, mulher latina, só para exemplificar a longa lista das que ficam de fora. Nomear-se mulher para mulheres negras é um território em disputa por tangenciar o espaço tenso de uma identidade colonialmente inventada: a da mulher branca, essa sim pensada como modelar desde a gênese da História das Mulheres.

Parece que nosso lugar tá dado, posto na sociedade. É estrutural. Mulher preta é pobre; Mulher pobre é preta [...] com baixa escolaridade, ocupando a base da pirâmide no mercado de trabalho, pelo menos na sua maioria. Nesse ponto, recorro mais uma vez ao pensamento de Ângela Davis: 'precisamos pensar o quanto o Racismo impede a mobilidade social da população negra'. Enquanto a faxina for preta, exclusiva das mulheres pretas, vamos ter que enfrentar esse desafio pós-moderno, colonizado - reafirmar a todo momento quem somos. E a pele preta ainda nos marca e nos mata na escala inferior da sociedade. No nosso caso, a história é diferente. O buraco é mais embaixo. Ou, parafraseando Lélia Gonzalez, 'Cumé qui é', por que é o Racismo que nos dilacera. (PIEDADE, 2017, online).

Exato. "Cumé qui é" que ainda se mantém esse silêncio colocado nas pesquisas sobre gênero que deixam a raça de fora e apontam para a reificação de uma única identidade feminina, a branca? A resposta nos leva de volta ao feminismo e às articulações dele com o silêncio racial, bem como à pactuação com as opressões de raça e classe. Importante evidenciar que a construção do feminismo é historicamente marcada pela presença de mulheres brancas que tomaram para si a alcunha de feministas. Ademais, é desse grupo, em grande parte, que nasceram as produções acerca de mulheres no Brasil. Daí a importância de pensar esse sujeito branco como ocupante de um espaço repleto de simbolismos no que se refere aos lugares e às possibilidades que lhe são acessíveis, originados e mantidos pelos privilégios da herança colonial.

Essas âncoras são fatores fundamentais quando se pensa na produção de uma escrita acadêmica sobre mulheres pretas, já que todo processo implica a desnaturalização dos lugares dados. Sendo assim, pesquisadoras brancas, produtoras das discussões sobre gênero, não estão imunes ao feitiço da branquidade. Além disso, suas pesquisas são marcadas por relações de poder intragênero que hierarquizam identidades e as essencializam a partir da assunção de que é possível pensar gênero à margem da raça.

Quando se considera que não há apenas diferenças entre as mulheres, mas relações de privilégio, torna-se difícil operar com o entendimento de que há alguma base comum a todas elas sem incorrer numa visão 
naturalista, ancorada no sexo biológico. Ao mesmo tempo, a ideia de que haveria uma solidariedade decorrente do fato de ser mulher em sociedades nas quais o sexismo implica desvantagens para elas e vantagens para eles esbarra nas hierarquias entre as mulheres, com as formas alternativas de solidariedade (e, novamente, privilégio) a que correspondem. Na compreensão do gênero como construção que não se produz isoladamente, mas em diferenciações que se definem racialmente, as mulheres brancas são situadas em um polo de poder e de violência. (WERNECK, 2010, p. 11).

Brah (2006) já advertia sobre a impossibilidade de analisar de forma isolada as questões que afetam mulheres em cada uma das suas especificidades, mas também atenta para a ilusão perigosa trazida pela universalização simplificante, ressaltando a necessidade de tratar a pluralidade de subjetivação do feminino e suas expressões nas relações sociais pensando-as "como práticas discursivas não essencialistas e historicamente contingentes" (BRAH, 2006, p. 358).

\section{Interseccionalidade: uma proposição epistemológica à história das mulheres}

Para Harding (1996), os estudos feministas deveriam tomar para si a responsabilidade de fazer uma crítica perene às formas estabelecidas de conhecimento, pautadas pelo androcentrismo e, de forma concomitante, desenvolver reflexões que, geradas a partir de novas epistemologias, produzam de fato reflexões plurais. Ou seja, romper com isso implica romper com um modelo de racionalidade que abre mão das matrizes explicativas totalizantes e permita abrir caminho para se pensar em novas epistemologias que acessem histórias muito velhas.

Novas epistemologias para acessar velhas histórias. Atingir o inatingível perguntando à mulher como fazer para capturar memórias de dor e invisibilidade. Mas, antes de perguntar, é preciso encontrar essa mulher volátil, já que, segundo Werneck (2010), mulheres negras não existem, pois são construções fruto da articulação de heterogeneidades. Resultam de demandas históricas, políticas, culturais e de enfrentamento das condições adversas estabelecidas pela dominação ocidental eurocêntrica ao longo dos séculos de escravidão, de expropriação colonial e da modernidade racializada e racista em que vivemos.

Nessas esquinas sobrepostas, mulheres negras foram relegadas a um plano menor pela historiografia, ocupando no campo de pesquisas o mesmo lugar que Ihes foi legado pela tradição escravocrata: o da subalternidade invisível. Alijadas e empurradas para as margens, permaneceram no limbo ou encarceradas pelas leituras estereotipadas, até que assumissem 
o legado de escrever sua própria história, desenvolvendo uma epistemologia que desse conta da multiplicidade de suas trajetórias.

E foi das articulações dos movimentos de mulheres não brancas que Kimberlé Crenshaw (1991) pinçou e sintetizou ferramentas de pesquisa doravante batizadas de interseccionalidade. Embora não trouxesse nenhuma novidade nos processos de ativismo, a interseccionalidade permitiu a instrumentalização de uma nova perspectiva de análise que contempla as abordagens sobre a mulher, em especial a mulher negra. Apesar de já apresentada em elaborações anteriores, aparecia agora como um conceito, um método de pesquisa, forjado a partir da interação entre formas de opressão e o debate sobre de que forma ações e políticas específicas geram mecanismos que atuam com o objetivo de desempoderar mulheres negras.

Ao colocar uma lupa sobre mulheres negras, pensando-as a partir de sua subalternidade, em todos os espaços em que circulam, e em como viver nesses lugares gerou experiências e conhecimentos essenciais para a compreensão de questões sociais fundamentais sobre as identidades femininas, Kimberlé Crenshaw (1991) extraiu um forma de analisar porque, para mulheres negras, tudo era tão inacessível. Identificando-se como feminista negra, ela abriu um nicho novo de análise, com uma epistemologia particular, que passou a adotar como cerne as relações entre experiência de mulheres negras e conhecimento interseccional.

Essa experiência não pode ser compreendida apenas a partir de sua condição de mulher, devendo-se considerar todos os sistemas de poder que afetam sinergicamente suas existências. Implícito ao conceito está a compreensão dos processos degradantes de subjetivação de mulheres, seus recortes de raça, sua ligação com a subalternidade e com a luta de mulheres negras, bem como com a formação de mulheres enquanto sujeitos políticos que reivindicam espaços de fala e instâncias de poder

Interseccionalidade permite às feministas criticidade política a fim de compreenderem a fluidez das identidades subalternas impostas a preconceitos, subordinações de gênero, de classe e raça e às opressões estruturantes da matriz colonial moderna de onde saem. (AKOTIRENE, 2018, p. 33).

Rapidamente o conceito de interseccionalidade ganhou a simpatia de pesquisadores de gênero que viram nele uma panaceia para potencializar suas análises a partir de generalizações do uso, despido de sua motriz primeira: a que define que a interseccionalidade implica ação política, seja nas elaborações teóricas, seja na atuação em movimentos sociais, algo ainda incompreensível à grande maioria de pesquisadores que se apropriam do termo.

Instala-se assim uma segunda forma de invisibilizar mulheres negras na produção historiográfica, pois, descolada de sua perspectiva social, a interseccionalidade vem sendo abraçada por diversas áreas como um 


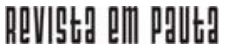

\} E EU (AINDA) NÃO SOU UMA MULHER - CASTRO, G. C. \}

DOI: $10.12957 /$ rep.2021.56086

projeto de conhecimento de grande aceitação acadêmica. Dessa maneira, dá oportunidade a pesquisadores de gênero, que antes caminhavam separados em suas áreas estanques, para que pudessem contrastar os estudos sobre mulheres nas disciplinas distintas e usar suas conclusões em produções que, como autoafirmado, se apoiam nas análises interseccionais para explicar seus resultados. Essa migração do movimento social para a perspectiva acadêmica permite ao interseccional se manter afirmando-se efetivamente interseccional? Depende de quem e de como a usa. Patrícia Hill levantou essa questão indagando o que se perdeu na tradução:

O que sobreviveu na migração do feminismo negro para a academia e seu recondicionamento como uma cada vez mais legítima interseccionalidade? De que forma os vínculos da interseccionalidade com a política emancipatória foram renegociados, em sua pesquisa crítica e suas práxis, em resposta às normas acadêmicas, tantas vezes antitéticas? O que se perdeu na tradução? Muitos temas são alimento para o pensar. [...] há uma diferença entre acreditar nos princípios éticos como um suporte para a igualdade de agir segundo eles. A ética está no cerne do feminismo negro, cuja razão de ser consiste em desmantelar as injustiças sociais de raça, classe, gênero e sexualidade, que produzem desigualdades sociais nas experiências das mulheres de cor. (COLLINS, 2017, p.14).

Parida do intelecto e da experiência de mulheres negras, a interseccionalidade foi transformada em ferramenta epistêmica da academia engessada, embranquecida, eurocentrada e pasteurizada em toda sua potência para pensar a mudança. Pesquisadores fizeram vista grossa ao fato de que o conceito está diretamente ligado à questão racial e passaram a utilizá-lo para analisar corpos que usufruem dos benefícios da exploração de outros. Interseccionalidade não é uma chave universal que serve para dar visibilidade a sujeitos de pesquisa até então ignorados ou parcialmente analisados. Ela é uma operação potente nascida ao refutar o enclausuramento e a hierarquização dos grandes eixos da diferenciação social, que são as categorias de sexo/gênero, classe, raça, etnicidade, idade, deficiência e orientação sexual.

Enquanto ferramenta de pesquisa, portanto, a interseccionalidade envolve uma orientação para estudos que consigam desenhar narrativas apoiadas na percepção de que as pessoas não são fragmentadas e essencializadas por situações particulares. Ou seja, implica a necessidade de enxergar que as opressões as atingem de modo combinado, coexistindo e reforçando-se mutuamente na produção das desigualdades sociais. Assim, obriga-se o historiador a analisar essas opressões numa perspectiva temporal que utilize como pistas as expressões que carrega e os efeitos que produz, tendo a raça como horizonte primeiro. A isso soma-se a necessidade da adoção de metodologias que alcem desvendar em suas leituras as 
configurações de diferenciações sociais e de possíveis desigualdades em termos contextualizados histórica e culturalmente.

Em vez de somar identidades, analisa-se quais condições estruturais atravessam corpos, quais posicionalidades reorientam significados subjetivos desses corpos, por serem experiências modeladas por e durante a interação das estruturas, repetidas vezes colonialistas, estabilizadas pela matriz e opressão, sob a forma de identidade. Por sua vez, a identidade não pode se abster de nenhuma das suas marcações, mesmo que nem todas, contextualmente estejam explicitadas. (AKOTIRENE, 2018, p. 43).

Sem a raça, a interseccionalidade, nascida para sistematizar o "conhecimento situado de mulheres negras como instrumento normativo [...] como uma sensibilidade hermenêutica no campo da teoria crítica feminista de raça" (AKOTIRENE, 2018, p. 45), acaba esvaziada. Transformada em modinha acadêmica, é apropriada por pesquisadoras eivadas de branquitude e completamente incapazes de entender sua potência em catapultar mulheres não brancas para espaços de protagonismo que culminem, de fato, em políticas de reversão da ótica colonial. Não há nenhuma brecha para uso do conceito que se afaste da compreensão de suas interrelações com a geografia da colonialidade, que serviu de base modelar para enquadrar identidades a partir da lógica do capital que referendou as violências perpetradas ao continente africano.

A estruturação da semântica da interseccionalidade é fruto das lutas das mulheres negras, e isso é insuportável e incompreensível a identidades e corpos que são perpassados por privilégios, sejam esses de raça, classe ou gênero. A passividade das esquinas deve ser substituída pelas colisões violentas, pelos encontros abruptos e pelas violações impostas para que se alcance a forma como o interseccional se elabora.

[...] prefiro as metáforas de acidentes para a aplicação prática da interseccionalidade. Opto 'amefricanizar' a retórica análoga à Lélia Gonzalez, usando a encruzilhada como o lugar multideterminado dos trânsitos de raça, classe, gênero, sexualidade, fluxos e sobreposições de acidentes identitários. As mulheres negras são frequentemente vitimadas por estarem mais vezes posicionadas nas avenidas da diferença, interdependência e interação estruturais. Inevitavelmente, o socorro político da cosmovisão ocidental agrava o estado social duma vítima enxergada diferente da mulher universal e os seus sentidos de humanidade sequer serem auferidos. A mulher negra na avenida do acidente não pode contar com a assistência feminista, pois que a raça retira as condições do socorro, as ferramentas trazidas são brancocếntricas. Por sua vez, o socorro do movimento antirracista vem à procura da raça, ao se deparar com gênero desconsidera a multidimensionalidade do acidente e da vítima mulher. De tal modo, mulher negra gendrificada, é quem produz, sozinha, as condições 
ancestrais de se levantar contra os impactos coloniais, políticos e jurídicos. (AKOTIRENE, 2019, online)

Definição, teoria, ferramenta metodológica ou heurística: pesquisadores que abracem a interseccionalidade necessitam atentar para a centralidade da análise das relações de poder intrínsecas a ela. Mais uma vez, intelectuais negras avançaram nessa discussão deixando evidente a inexistência de uma solidariedade intragênero e apontando o dedo para as inúmeras diferenças e desigualdades entre mulheres de distintos lugares sociais, experiências religiosas, pertença racial, orientação sexual e de classe, todas oriundas de uma percepção aguda: mulheres brancas jamais pariram amarradas a um tronco para que sua prole reproduzisse as relações do capital. Essa radiografia revelou a multiplicidade de identidades femininas e de ações políticas a elas vinculadas. Além disso, conseguiram trazer à tona as diversas formas de opressão impostas por mulheres brancas a mulheres negras, cuja submissão foi, em diversos momentos históricos, ferramenta de libertação para as primeiras, pois

de nada adianta intelectuais defenderem a descolonização do feminismo sem legitimar negrura perspectivista em nível psíquico, cognitivo, e espiritual das epistemes. O conceito de interseccionalidade está em disputa acadêmica, há saqueamento de riqueza conceitual e apropriação do território discursivo feminista negro para feminismo interseccional, retirando o paradigma afrocêntrico. A proposta de conceber a inseparabilidade do cisheteropatriarcado do racismo e do capitalismo está localizada no arcabouço teórico feminista negro, e quem o nega comete epistemicídio e racismo epistêmico. (AKOTIRENE, 2018, p. 38).

\section{Considerações finais}

Da experiência acadêmica e empírica de pesquisadoras pioneiras, podemos tirar alguns parâmetros norteadores para um horizonte metodológico acerca de mulheres negras numa perspectiva interseccional originalmente afrocêntrica. Num prisma primeiro, acredito ser necessário abrir mão do pensar mulher na singularidade e aprofundar o significado do termo enquanto categoria polissêmica, complexa e tensa em suas disputas intestinas, perpassada por variáveis identitárias, temporais e territoriais que interferem em suas possibilidades de protagonismo. Isso implica rastrear como essas mulheres veem o mundo; ademais, a forma com que são vistas e expectadas impacta em seus pontos de vista e em suas construções de narrativas.

Nem nova, nem fechada, nem unívoca, a interseccionalidade colocou em pauta a complexidade do fato de que são muitas as possibili- 
dades de pensar e usar as lentes oferecidas por esse conceito para pensar a historiografia das mulheres, exatamente porque mulheres não se constituem num bloco sólido e homogêneo. Desafia assim a um pensar que resulte em uma análise perpassada pela complexidade de compreender como diferentes mulheres lidaram com o desafio de alcançar visibilidade e protagonismo em diferentes contextos sociopolíticos.

Se mulher é um objeto múltiplo, situá-la nas colisões que a atropelam faz-se essencial para compreender que vetores de exclusão recaem sobre ela, analisando ao mesmo tempo como é feita a distribuição de poder na sociotemporalidade em que ela se insere, como também para pensar quais construções discursivas são feitas sobre ela, quem as produz, e se e como essas mulheres são afetadas pela marginalização econômica e racial.

Isso envolve investigar como se constroem os discursos que organizam e validam as opressões e articulam subalternidades, bem como de que forma as vozes subalternas constroem contranarrativas a partir desses discursos. Implica um esforço de não cair na armadilha de acabar reproduzindo em nossas pesquisas as perspectivas que investigamos, usando como ponto de partida análises que tratam as categorias como fechadas, deslegitimando sua fluidez e as mudanças nas representações sociais. "De pronto a interseccionalidade sugere que a raça traga subsídios de classe-gênero e esteja em um patamar de igualdade analítica. Raça é a maneira como a classe é vivida" (AKOTIRENE, 2019, p. 32).

Então, se a interseccionalidade tem como veio mais fértil as articulações entre raça, classe e gênero, e se sua origem está ligada aos movimentos sociais, proponho pensar que a interseccionalidade é um termo também historicizado uma vez que oculta variáveis analíticas que devem ser levadas em conta na medida em que fareja o fluido e o transitório. Uma tarefa de peso se assoma nesse fazer epistêmico, ressignificado pela urgência de atentarmos para a necessidade da elaboração de narrativas que se construam a partir de diálogos pautados pela escuta das falas subalternas e atravessados por reflexões que nos oportunizem enxergar a capacidade reflexiva, de diálogo, agência e resistência que jorra desses espaços de opressão, bem como sua contribuição na desestabilização das falas hegemônicas (HOOKS, 2019).

Temos posto um dilema que se coloca em diversas camadas: o desafio de tecer uma história das mulheres que entrelace a construção de subjetividades negras numa sociedade diaspórica, frente a estereótipos degradantes que desembocam em narrativas distorcidas, precarizadas ou inexistentes, marcadas pelo racismo, pelo sexismo, pelo colonialismo e pela branquitude, na busca de uma história de mulheres, de fato, plurais. 


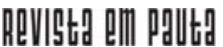

\} E EU (AINDA) NÃO SOU UMA MULHER - CASTRO, G. C. \}

DOI: $10.12957 /$ rep.2021.56086

\section{Referências}

AKOTIRENE, C. O que é interseccionalidade? Belo Horizonte: Letramento, 2018.

AKOTIRENE, C. Ferramenta anticolonial poderosa: os 30 anos de interseccionalidade. 2019. Disponível em: https://www.cartacapital.com.br/opiniao/ ferramenta-anticolonial-poderosa-os-30-anos-de-interseccionalidade/. Acesso em: 15 set. 2019.

BRAH, A. Diferença, diversidade, diferenciação. 2006. Disponível em: http:/ /scielo.br/pdf/cpa/n26/30396.pdf. Acesso em: 13 nov. 2019.

COLLINS, P. H. Se perdeu na tradução? Feminismo negro, interseccionalidade e política emancipatória. 2017. Disponível em: http://revistas eletronicas. fiamfaam.br/index.php/recicofi/article/view/559. Acesso em: 25 jul. 2018.

CRENSHAW, K. W. Mapping the margins: intersectionality, identity politics and violence against women of color. Stanford Law Review, v. 32, n. 6, 1991. HARDING, S. Ciência y feminismo. Madrid: Morata, 1996.

HOOKS, B. Erguer a voz: pensar como feminista, pensar como negra. São Paulo: Elefante, 2019.

MATOS, M. I. S. de M. História das mulheres e das relações de gênero: campo historiográfico, trajetórias e perspectivas. Revista Mandrágora, São Paulo, v. 19, n. 19, 2013.

PIEDADE, V. A cor da faxina no Brasil. Disponível em: http://www.justi cadesaia.com.br/a-cor-da-faxina-no-brasil/. Acesso: em 28 jul. 2018.

RAGO, M. As mulheres na historiografia brasileira. In: SILVA, Z. L. (Org.). Cultura histórica em debate. São Paulo: Unesp, 1995.

RATTS, A. Eu sou Atlântica: sobre a trajetória de vida de Beatriz Nascimento. São Paulo: Instituto Kwanza, 2006.

WERNECK, J. Nossos passos vêm de longe! Movimentos de mulheres negras e estratégias políticas contra o sexismo e o racismo. Revista da $A B P N$, Rio de Janeiro, v. 1, n. 1, 2010.

DOI: $10.12957 /$ rep.2021.56086

Recebido em 09 de março de 2020.

Aprovado para publicação em 02 de julho de 2020.

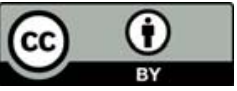

A Revista Em Pauta: Teoria Social e Realidade Contemporânea está licenciada com uma Licença Creative Commons Atribuição 4.0 Internacional. 